\title{
TRENDS IN THE DEVELOPMENT OF THE EXTERNAL ENVIRONMENT OF ENTREPRENEURSHIP IN THE REPUBLIC OF KAZAKHSTAN
}

\author{
Olga V. Mishulina \\ Kostanay Branch of Chelyabinsk State University, Kostanay, Republic of Kazakhstan \\ Galina V. Panina \\ Kostanay Branch of Chelyabinsk State University, Kostanay, Republic of Kazakhstan \\ Natalya A. Baranova \\ Kostanay Branch of Chelyabinsk State University, Kostanay, Republic of Kazakhstan \\ Natalya S. Gorelova \\ Kostanay Branch of Chelyabinsk State University, Kostanay, Republic of Kazakhstan
}

\begin{abstract}
This article is devoted to the impact of the external environment on the development of entrepreneurship in Kazakhstan. The aim of the study is to identify current trends in the external environment of indirect effects on entrepreneurship based on the quantitative and qualitative analysis. The authors analyze strengths and weaknesses of small and medium enterprises, contribution of this sector to the development of the economy of Kazakhstan. The paper reveals advantages and disadvantages of the state and integration subsystem of the external environment of entrepreneurship, providing financial and non-financial support measures that are factors of sustainable economic development of Kazakhstan. The authors use the data of the Committee on Statistics of the Ministry of National Economy of the Republic of Kazakhstan, annual reports of "Damu Entrepreneurship Development Fund" JSC. Methods of scientific knowledge, comparison, analysis, and systematic I approach are applied as the main research methods. The main result of the study is formulating modern trends in the ते state and development of the external environment of entrepreneurship in Kazakhstan. Unfavorable trends identified $\tilde{j}$ by the authors will help substantiate the main directions of increasing the efficiency of small and medium enterprises. i Based on the quantitative and qualitative analysis of the state and integrated subsystem of the external environment of entrepreneurship, the authors draw conclusions about its impact on the state and development of small and medium enterprises.
\end{abstract}

Key words: small and medium enterprises, external environment, credit regulation, tax regulation, customs regulation, development institutions, public-private partnerships.

Citation. Mishulina O.V., Panina G.V., Baranova N.A., Gorelova N.S. Trends in the Development of the External Environment of Entrepreneurship in the Republic of Kazakhstan. Journal of Volgograd State University. Economics, 2020, vol. 22, no. 1, pp. 55-67. (in Russian). DOI: https://doi.org/10.15688/ ek.jvolsu.2020.1.6

\section{ТЕНДЕНЦИИ РАЗВИТИЯ ВНЕШНЕЙ СРЕДЫ ПРЕДПРИНИМАТЕЛЬСТВА В РЕСПУБЛИКЕ КАЗАХСТАН}

\section{Ольга Владимировна Мишулина}

Костанайский филиал Челябинского государственного университета, г. Костанай, Республика Казахстан 
Галина Викторовна Панина

Костанайский филиал Челябинского государственного университета, г. Костанай, Республика Казахстан

\section{Наталья Аркадьевна Баранова}

Костанайский филиал Челябинского государственного университета, г. Костанай, Республика Казахстан

Наталья Сергеевна Горелова

Костанайский филиал Челябинского государственного университета, г. Костанай, Республика Казахстан

Аннотация. Настоящая статья посвящена вопросам влияния внешней среды на развитие предпринимательства в Республике Казахстан (далее - РК). Целью исследования становится выявление современных тенденций состояния и развития внешней среды предпринимательства на основе количественного и качественного анализа. В ходе исследования авторами проанализированы сильные и слабые стороны современного состояния малого и среднего предпринимательства, вклад данного сектора в развитие экономики Казахстана. Выявлены преимущества и недостатки государственной и интеграционной подсистемы внешней среды предпринимательства, обеспечивающие финансовые и нефинансовые меры поддержки, что является одним из основных факторов устойчивого экономического развития РК. В ходе подготовки данной статьи авторами были использованы данные Комитета по статистике Министерства национальной экономики РК, годовые отчеты АО «Фонд развития предпринимательства “Даму”». В качестве основных методов исследования были применены методы научного познания, сравнение, анализ, системный подход. Основным результатом исследования является формулирование современных тенденций состояния и развития внешней среды предпринимательства в РК. Выявленные авторами неблагоприятные тенденции будут способствовать обоснованию основных направлений повышения эффективности деятельности малого и среднего бизнеса в стране. Авторами на основе количественного и качественного анализа государственной и интегрированной подсистемы внешней среды предпринимательства сделаны выводы о ее влиянии на состояние и развитие малого и среднего предпринимательства (далее-МСП) в стране.

Ключевые слова: малое и среднее предпринимательство, внешняя среда, кредитное регулирование, налоговое регулирование, таможенное регулирование, институты развития, государственно-частное партнерство.

Цитирование. Мишулина О. В., Панина Г. В., Баранова Н. А., Горелова Н. С. Тенденции развития внешней среды предпринимательства в Республике Казахстан // Вестник Волгоградского государственного университета. Экономика. - 2020. - Т. 22, № 1. - C. 55-67. - DOI: https://doi.org/10.15688/ek.jvolsu.2020.1.6

\section{Введение}

Экономическая реформа, осуществляемая в РК в течение трех десятилетий, привела к появлению многоукладного рыночного хозяйства и свободного предпринимательства во всех 14 регионах страны. На формирование и развитие предпринимательской деятельности на современном этапе оказывают наибольшее влияние экономические факторы организационной среды, представляющие собой совокупность форм и методов управления и хозяйствования, экономических рычагов и стимулов [Аганбегян, 2005; Райзберг и др., 2011].

Экономическая наука имеет определенные достижения в разработке вопросов предпринимательства. Итогом многолетних исследований, особенно активно ведущихся в пос- ледние годы в РК, явилось развитие научных основ теории предпринимательства [Идрисов, 2015; Притворова и др., 2017; Шувалов, 2015]. Вместе с тем изучение имеющихся по данной проблеме теоретических разработок показало, что специальных исследований, касающихся влияния переменных внешней среды на формирование и развитие предпринимательства и оценки его функционирования, которые направлены на практические рекомендации по развитию предприимчивости, инициативы и адаптации в регионах Казахстана, крайне мало. Если политические факторы внешней среды дают представление о намерениях органов государственной власти в отношении развития общества и о средствах, с помощью которых государство предполагает претворять в жизнь свою политику, то экономические факторы в большей мере касаются 
функционирования непосредственно самих предпринимателей. Они включают экономические методы, рычаги и стимулы воздействия со стороны государства и общества на предпринимателей, взаимоотношения между ними. Экономические факторы внешней среды предпринимательства рассматриваются как комплекс взаимосвязанных явлений и отношений между инструментами экономической политики, которые направлены на стимулирование экономических агентов принять такую модель поведения, принятия решений, которая отвечает целям и задачам этой политики [Шишкин, 2013, с. 29]. Для предпринимателей это является важнейшим условием их деловой активности, а также обеспечивает увязку и согласование общественных, групповых и частных интересов, служит функционированию и развитию национальной экономики.

В настоящее время поиск путей адаптации предпринимательства ко внешней среде и меры по усилению государственной поддержки и активизации его развития предусмотрено считать приоритетной сферой государственной экономической политики РК.

\section{Тенденции развития}

\section{малого и среднего предпринимательства} в Республике Казахстан

Проанализируем современное состояние и динамику развития МСП в РК, поскольку они выступают индикатором адаптации предпринимательства ко внешней среде. Количество зарегистрированных субъектов малого и среднего предпринимательства превысило 1,5 млн единиц и выросло на 33 тыс. единиц, или на 2,1 \% (табл. 1). При этом их доля в общем количестве хозяйствующих субъектов в стране увеличилась до 96,7 \%. Быстрыми темпами растет количество малых и средних предприятий в обрабатывающей промышленности. Так, за анализируемый период удельный вес предприятий обрабатывающего сектора в общем количестве субъектов МСП вырос с 2,7 \% до 3,2 \%. Число активно действующих субъектов МСП в РК увеличилось на 273 тыс., или в 1,3 раза, а их доля в общем количестве зарегистрированных - на 16,1 п.П., что свидетельствует о сокращении в секторе количества номинальных игроков и одновременно появлении действующих субъектов предпринимательства.

Имеющееся число действующих субъектов МСП в РК (на 1000 жителей Казахстана приходится в среднем 82,8 организаций малого и среднего бизнеса) достаточно для возрастания их роли в экономике страны.

По организационно-правовым формам наибольший удельный вес в структуре действующих субъектов МСП занимают индивидуальные предприниматели (далее - ИП), осуществляющие предпринимательскую деятельность без образования юридического лица $-65,5$ \% (см. рис. 1). При этом доля предприятий МСП в форме юридического лица увеличилась в 2018 г. по сравнению с 2013 г. на 11 п.п., одновременно происходит снижение доли ИП на 8,5 п.п. Это свидетельствует о качественном институциональном развитии малого и среднего бизнеса за счет создания новых юридических лиц и перерегистрации ИП в товарищества с ограниченной ответственностью (далее - ТОО).

Таблица 1

Динамика количества зарегистрированных субъектов МСП в Республике Казахстан

\begin{tabular}{|l|c|c|c|c|c|c|}
\hline \multicolumn{1}{|c|}{ Показатели } & \multicolumn{5}{|c|}{ Годы } \\
\cline { 2 - 8 } & 2013 & 2014 & 2015 & 2016 & 2017 & 2018 \\
\hline Зарегистрированные субъекты, тыс. ед. & 1536 & 1656 & 1530 & 1501 & 1540 & 1569 \\
\hline Действующие субъекты МСП, тыс. ед. & 968 & 1011 & 1290 & 1106 & 1146 & 1241 \\
\hline в том числе обрабатывающей промышленности & 21,7 & 22,9 & 26,1 & 38,1 & 37,8 & 36,3 \\
\hline $\begin{array}{l}\text { Доля зарегистрированных субъектов МСП в об- } \\
\text { щем количестве хозяйствующих субъектов, \% }\end{array}$ & 95,1 & 95,6 & 96,2 & 96,1 & 96,2 & 96,7 \\
\hline $\begin{array}{l}\text { Доля действующих субъектов МСП в общем ко- } \\
\text { личестве зарегистрированных, \% }\end{array}$ & 63,0 & 61,0 & 84,3 & 73,7 & 74,4 & 79,1 \\
\hline $\begin{array}{l}\text { Доля действующих субъектов МСП обрабаты- } \\
\text { вающей промышленности, \% }\end{array}$ & 2,7 & 2,6 & 2,8 & 3,0 & 3,2 & 3,2 \\
\hline
\end{tabular}

Примечание. Составлено авторами по: [Влияние программ ..., 2018, с. 7; Отчет ... , 2018, с. 128]. 
Общее число постоянно работающих в МСП в РК на 1 января 2018 г. составило 3268 тыс. чел., или 37,5\% активного населения страны, что на 27,8 \% больше по сравнению с 2013 г. (табл. 2). Это свидетельствует о растущем значении предпринимательства в решении проблемы занятости населения в Казахстане.

При этом по сравнению с развитыми странами в Казахстане этот индикатор в 1,5-2 раза ниже. Наблюдается положительная тенденция в создании рабочих мест на предприятиях МСП обрабатывающего сектора РК. За период 2013-2018 гг. численность населения, занятого в этом секторе экономики страны, выросла на 64,6 тыс. и достигла 252,8 тыс. человек. Это привело к увеличению вклада МСП в занятость населения в обрабатывающей промышленности РК за анализируемый период с $34,6 \%$ до 43, $5 \%$.

Для обеспечения стабильной экономики, ее диверсификации и отхода от сырьевой направленности в Казахстане поставлена стра- тегическая задача довести долю продукции МСП в ВВП страны не менее $50 \%$, однако за анализируемый период величина этого показателя колеблется в пределах 16,9-28,9 \% (см. табл. 3). Важно отметить растущую роль МСП в формировании обработанной продукции с высокой добавленной стоимостью. Так, за рассматриваемый период выпуск продукции МСП обрабатывающей промышленности вырос на 1714 млрд тенге или в 2,7 раза.

Доля валовой добавленной стоимости (далее - ВДС) МСП в ВВП в 2018 г. оценивается в $28,9 \%$. Доля продукции МСП в общем объеме продукции обрабатывающей промышленности выросла на 10,6 п.п. и составила $28,8 \%$ (что превышает показатель доли вклада МСП в ВВП). Это характеризует положительную тенденцию в структуре казахстанского бизнеса - отход от сырьевой направленности.

Структура субъектов МСП в разрезе отраслей экономики является важным показателем качественного развития предприни-

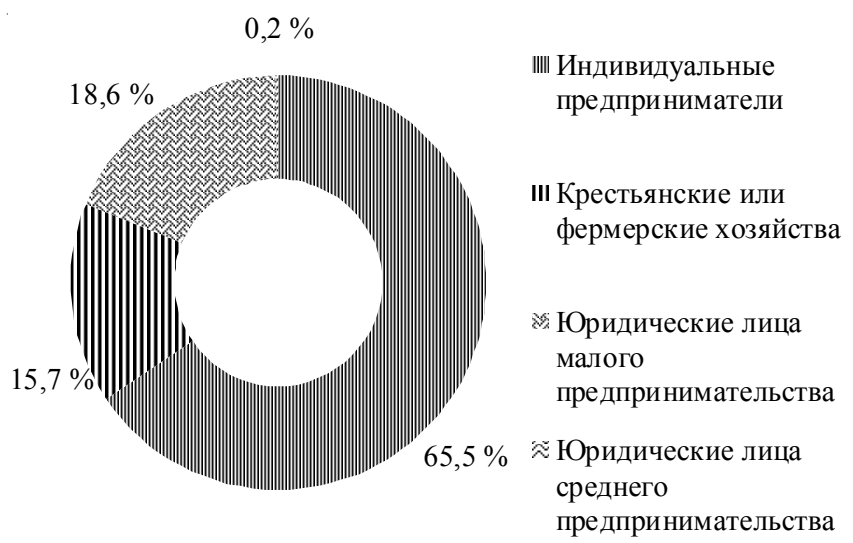

Рис. 1. Структура активных субъектов МСП по организационно-правовым формам Республики Казахстан, 2018 год

Примечание. Составлено авторами по: [Малое и среднее предпринимательство].

Таблииа 2

Динамика доли населения, активно занятого в МСП в Республике Казахстан

\begin{tabular}{|l|c|c|c|c|c|c|}
\hline \multicolumn{1}{|c|}{ Показатели } & \multicolumn{5}{|c|}{ Годы } \\
\cline { 2 - 7 } & 2013 & 2014 & 2015 & 2016 & 2017 & 2018 \\
\hline Занятое в экономике население, тыс. чел. & 8571 & 8510 & 8624 & 8553 & 8585 & 8704 \\
\hline Численность активно занятых в МСП, тыс. чел. & 2557 & 2770 & 3147 & 3167 & 3145 & 3268 \\
\hline $\begin{array}{l}\text { Занятые в МСП обрабатывающей промышленно- } \\
\text { сти, тыс. чел. }\end{array}$ & 188,2 & 192,5 & 210,3 & 241,4 & 237,5 & 252,8 \\
\hline Доля МСП в обеспечении занятости населения, \% & 30,1 & 32,5 & 36,5 & 37,0 & 36,6 & 37,5 \\
\hline $\begin{array}{l}\text { Доля МСП в обрабатывающей промышленности } \\
\text { в обеспечение занятости населения, \% }\end{array}$ & 34,6 & 35,1 & 39,2 & 43,7 & 42,1 & 43,5 \\
\hline
\end{tabular}

Примечание. Составлено авторами по: [Влияние программ ..., 2018, с. 8; Годовой отчет ... , 2018, с. 15]. 
мательского сектора и экономики в целом. Около 30 \% субъектов МСП заняты в сфере оптовой и розничной торговли, 13 \% субъектов функционируют в сельском хозяйстве. В отраслевой структуре сектора МСП по трем основным показателям (количество субъектов, численность занятых и выпуск продукции) с 2013 г. сохраняются четыре основные тенденции. Во-первых, почти по всем показателям растет доля сферы услуг: в количестве субъектов - с $20 \%$ до $29 \%$, в численности занятых - с $21 \%$ до $31 \%$, в выпуске продукции - с $21 \%$ до $22 \%$. Во-вторых, наблюдается сокращение доли сельского хозяйства в количестве крестьянских или фермерских хозяйств и численности занятых. B-третьих, по предприятиям обрабатывающей промышленности в абсолютных значениях наблюдается рост: количество субъектов выросло в 1,7 раза, численность занятых - в 1,3 раза, а выпуск продукции - в 2,7 раза. В-четвертых, сохранилось неравномерное развитие сектора МСП в регионах Казахстана, которое объясняется неравномерным распределением населения и ресурсов, особенностями социально-экономического развития регионов страны, различиями в структуре их экономик, диспропорциями в финансировании сектора МСП между регионами. В 2013-2018 гг. более $73 \%$ всех средств банков, направленных на развитие МСП в 14 регионах страны приходилось на г. Нур-Султан и г. Алматы.

Положительная динамика по основным макроэкономическим индикаторам в секторе МСП сохранилась, показатели вклада сектора в развитие экономики РК продолжают расти, однако они все еще являются недостаточными для вхождения РК в число развитых стран. Это свидетельствует о необходимости анализа движущих сил, которые находятся вне сферы непосредственного контроля предпринимательства и могут оказать влияние на стратегию их функционирования и развития.

\section{Влияние внешней среды на предпринимательство Республики Казахстан}

Внешняя среда предпринимательства РК включает в себя совокупность элементов, которые объединяются в три подсистемы: государственную, рыночную и интеграционную (см. рис. 2).

Накопление денежного капитала является важнейшим условием развития МСП и осуществляется посредством деятельности кредитно-финансовой системы. Один из главных факторов, определяющих несбалансированную отраслевую и региональную структуру сферы МСП в Казахстане, - это несоответствующая низкая доля кредитов МСП в портфеле по кредитам экономики в целом по сравнению с долей выпуска продукции МСП в ВВП страны (см. рис. 3).

По данным Национального Банка РК, общие объемы банковского кредитования в 2018 г. по сравнению с 2013 г. выросли в 1,2 раза, составив 13,5 трлн тенге, при этом по показателю «доля кредитов на предпринимательские цели» наблюдается снижение с 78,5 \% до 69,9\% [Национальный банк ...]. Снижение доли банковского кредитования произошло в результате передачи проблемных кредитов банками второго уровня (далее БВУ) под управление специализированным компаниям, прекращения работы двух банков и сокращения объемов депозитов в банках. В связи с этим уменьшился и кредитный пор-

Таблица 3

\section{Вклад МСП в ВВП Республики Казахстан}

\begin{tabular}{|l|c|c|c|c|c|c|}
\hline \multicolumn{1}{|c|}{ Показатели } & \multicolumn{5}{c|}{ Годы } \\
\cline { 2 - 7 } & 2013 & 2014 & 2015 & 2016 & 2017 & 2018 \\
\hline ВВП, млрд тенге & 35275 & 38712 & 40878 & 46971 & 51967 & 58786 \\
\hline Выпуск продукции МСП, млрд тенге & 9165 & 14605 & 15858 & 16857 & 21148 & 26490 \\
\hline $\begin{array}{l}\text { Выпуск продукции МСП обрабатывающей про- } \\
\text { мышленности, млрд тенге }\end{array}$ & 993 & 1103 & 1571 & 1676 & 2534 & 2707 \\
\hline $\begin{array}{l}\text { Доля МСП в общем выпуске продукции обраба- } \\
\text { тывающей промышленности, \% }\end{array}$ & 18,2 & 18,9 & 25,8 & 28,1 & 31,5 & 28,8 \\
\hline Доля ВДС МСП в ВРП, \% & 16,9 & 26,2 & 25,6 & 26,8 & 25,6 & 28,9 \\
\hline
\end{tabular}

Примечание. Составлено авторами по: [Влияние программ ..., 2018, с. 8; Отчет ... , 2018, с. 128]. 
тфель БВУ в сегменте малого бизнеса. Именно поэтому основной упор в рамках госпрограмм в РК был сделан на расширение доступа МСП к кредитам через такие инструменты как субсидирование ставок, гарантирование кредитов и обусловленное размещение средств для дальнейшего финансирования малого и среднего бизнеса.

Анализ распределения кредитов банками МСП между областными центрами и другими городами и районами регионов Казахстана (без учета кредитов в городах Нур-Сул- тан и Алматы) показывает, что в целом по 14 областям Казахстана портфель кредитов вне областных центров по состоянию на 01.01.2018 составил 7,5 \% от совокупного кредитного портфеля МСП по 14 областям.

Некоторые виды кредитов предоставляются частному предпринимательству также инвестиционными фондами, микрокредитными финансовыми организациями (далее МФО), лизинговыми компаниями (далее- ЛК) и другими специализированными учреждениями. Низкий уровень информационной прозрач-

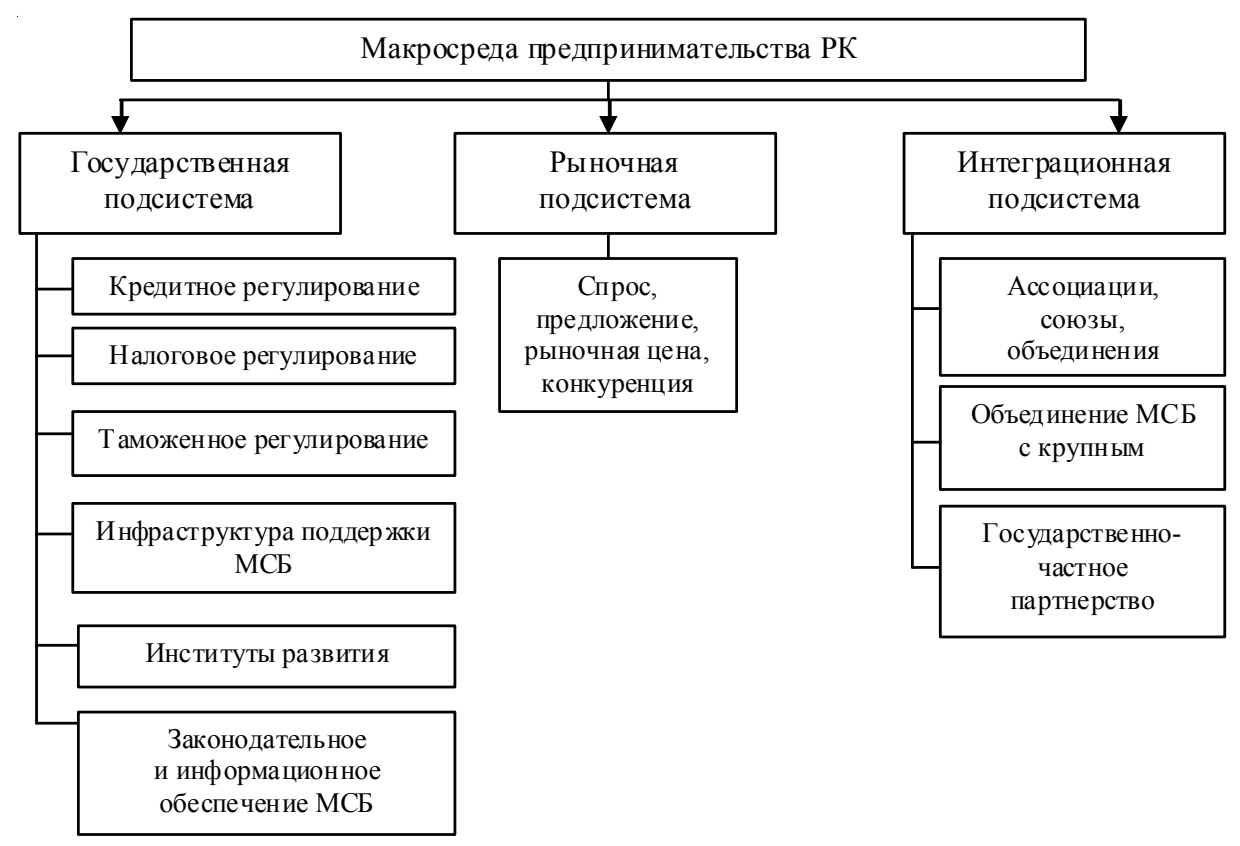

Рис. 2. Состав внешней среды предпринимательства в РК

Примечание. Составлено авторами по: [Райзберг и др., 2011; Шишкин, 2013].

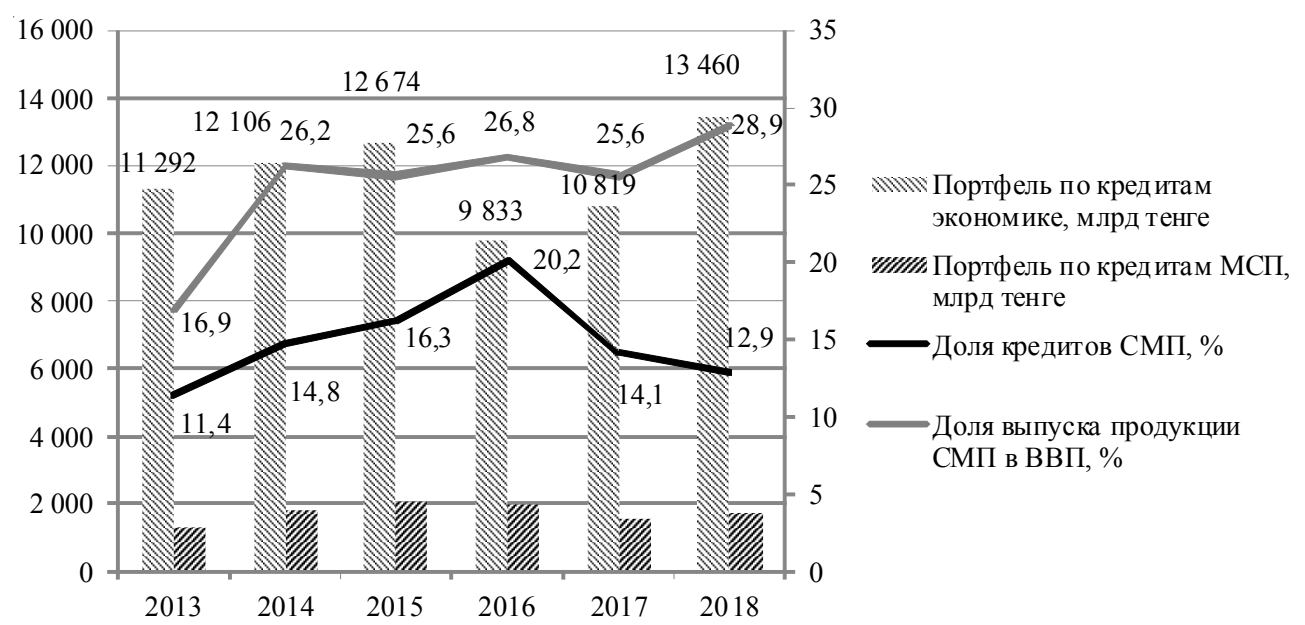

Рис. 3. Динамика кредитования субъектов МСП

Примечание. Составлено авторами по: [Влияние программ ..., 2018, с. 5; Годовой отчет ..., 2018, с. 16]. 
ности казахстанского рынка лизинга - один из главных факторов, тормозящих его дальнейшее развитие.

Расширение доступа малого и среднего бизнеса к кредитам, долгосрочное финансирование сроком до 7-10 лет активизировали его инвестиционную деятельность (табл. 4).

В 2012-2017 гг. годовой объем инвестиций в МСП вырос 2,1 раза, тогда как весь рыночный объем инвестиций - на 59,9\%, благодаря этому доля инвестиций в МСП в общем объеме инвестиций увеличилась с $33 \%$ до $43 \%$.

Как важнейший инструмент государственного регулирования бизнеса, система налогообложения в РК предусматривает специальные налоговые режимы для субъектов частного предпринимательства, чья деятель- ность представляет приоритетные интересы государства. Субъекты малого бизнеса в Казахстане имеют право самостоятельно выбирать наиболее приемлемый порядок исчисления и уплаты налогов, что приводит к ежегодному увеличению ими выплат по корпоративному подоходному налогу (далее - КПН) на фоне сокращения выплат от крупных и средних предприятий (рис. 4).

На протяжении анализируемого периода малые предприятия демонстрируют стабильный рост выплат по КПН - на 269 \%, а их доля в общих поступлениях от КПН составляет 23,2 \%. Аналогичная тенденция прослеживается и в малом бизнесе обрабатывающей промышленности. Вместе с тем 86,2 \% руководителей МСП в качестве главной причины, отрицательно влияющей на их экономи-

Динамика инвестиций МСП в основной капитал

Таблица 4

\begin{tabular}{|l|c|c|c|c|c|c|}
\hline \multicolumn{1}{|c|}{ Показатели } & \multicolumn{5}{|c|}{ Годы } \\
\cline { 2 - 7 } & 2012 & 2013 & 2014 & 2015 & 2016 & 2017 \\
\hline $\begin{array}{l}\text { Инвестиции всех хозяйствующих субъектов, } \\
\text { млрд тенге }\end{array}$ & 5473 & 6073 & 6591 & 7025 & 7762 & 8749 \\
\hline Инвестиции МСП, млрд тенге & 1822 & 1924 & 2831 & 2806 & 3119 & 3757 \\
\hline $\begin{array}{l}\text { Инвестиции МСП в обрабатывающую промыш- } \\
\text { ленность, млрд тенге }\end{array}$ & 611 & 687 & 729 & 825 & 878 & 982 \\
\hline Доля инвестиций МСП, \% & 33,0 & 32,0 & 43,0 & 40,0 & 40,0 & 43,0 \\
\hline $\begin{array}{l}\text { Доля инвестиций МСП в обрабатывающую про- } \\
\text { мышленность, \% }\end{array}$ & 11,0 & 11,0 & 11,0 & 12,0 & 11,0 & 11,0 \\
\hline Инвестиции за счет заемных средств, млрд тенге & 673 & 909 & 1131 & 1235 & 1419 & 1025 \\
\hline Доля инвестиций за счет заемных средств, \% & 12,0 & 15,0 & 17,0 & 18,0 & 18,0 & 12,0 \\
\hline
\end{tabular}

Примечание. Составлено авторами по: [Влияние программ ... , 2018, с. 6].

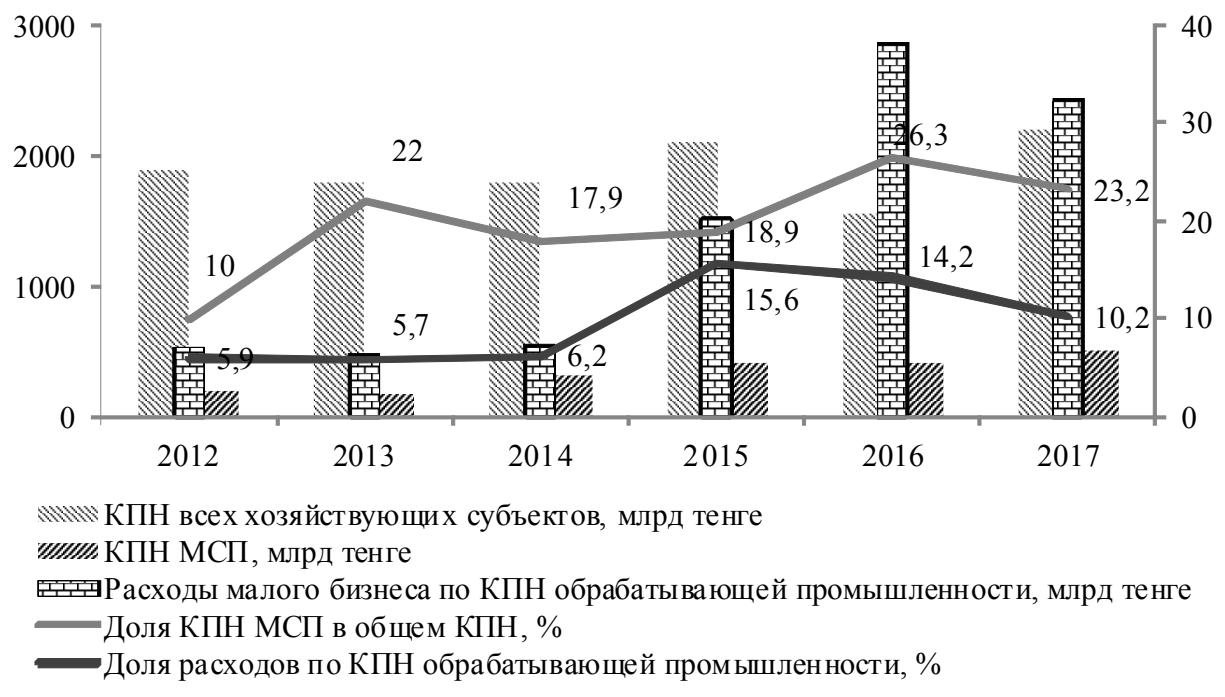

Рис. 4. Доля КПН МСП в общем КПН всех хозяйствующих субъектов

Примечание. Составлено авторами по: [Влияние программ ..., 2018, с. 11]. 
ческое положение, назвали несовершенство налогов, их высокий уровень и нестабильность, множество подзаконных актов, как правило, запаздывающих и нередко изменяющих цель самих законов. Такие условия не стимулируют предпринимателя на вложение капитала в отечественное производство.

Государство в РК берет на себя стратегические и координационные функции в экономических процессах развития частного предпринимательства. Одним из механизмов реализации этих функций являются институты развития (далее - ИР). Основным государственным институтом развития предпринимательства страны выступает АО «Фонд развития предпринимательства “Даму”», который имеет региональные филиалы во всех 14 областях Казахстана и городах Нур-Султан и Алматы. В своей основной деятельности «Даму» оказывает поддержку субъектам частного предпринимательства в рамках Единой программы «Дорожная карта бизнеса - 2020» (далее ДКБ-2020) посредством таких инструментов, как: 1) финансирование предпринимателей через обусловленное размещение средств в БВУ и лизинговых компаниях; 2) субсидирование ставки вознаграждения по кредитам и договорам финансового лизинга; 3 ) частичное гарантирование кредитов предпринимателей; 4) информационноконсультационная поддержка.

При рассмотрении вклада «Даму» с акцентом на финансирование приоритетных секторов экономики наблюдается снижение до 10,4 \%, что на 6,2 п.п. ниже показателей прошлого года (табл. 5).
Это связано с окончанием освоения средств, выделенных в рамках программы поддержки субъектов МСП в обрабатывающей промышленности за счет средств Национального Фонда в 2014-2015 гг. и изменением Стратегии развития Фонда в сторону увеличения количества поддержанных субъектов микро- и малого бизнеса. Таможенное регулирование для МСП в РК осуществляется на основе Таможенного Кодекса, общего для стран Таможенного союза. Результаты опроca 1600 предпринимателей, проведенные Центром исследований «Сандж» для Азиатского Банка Развития (далее - АБР) и «Фонда развития предпринимательства “Даму”» [Отчет ..., 2013] показали, что только 5,1 \% субъектов МСП вывозят свой товар на экспорт (Россия, Кыргызстан, Узбекистан, Таджикистан, Беларусь, Латвия, Турция и т. д.), а 31,6 \% ввозит сырье, комплектующие и материалы из-за границы (Россия, Украина, Беларусь, Кыргызстан, Турция, Германия, ОАЭ и т. д.). Таким образом, доля импортирующих субъектов МСП существенно превышает долю экспортирующих, что скорее свидетельствует о зависимости казахстанских субъектов МСП от внешних рынков, чем об активном освоении ими этих рынков.

По уровню активности на внешних рынках лидирует средний бизнес, который обладает сравнительно большими оборотами. Так, 43,4 \% предприятий среднего бизнеса закупают сырье, комплектующие и другие материалы преимущественно из-за рубежа. Остальные предприятия заметно реже осуществляют импорт сырья и материалов: малый бизнес - 33,3 \%, индивидуальные предпринима-

Таблица 5

\section{Динамика кредитов на проекты в приоритетных секторах экономики}

\begin{tabular}{|c|c|c|c|}
\hline Показатели & 2016 & 2017 & 2018 \\
\hline $\begin{array}{l}\text { Кредиты, выданные БВУ в приоритетных секторах экономики, } \\
\text { млрд тенге }\end{array}$ & 3219 & 2835 & 3732 \\
\hline в том числе кредиты в обрабатывающей промышл енности & 1493 & 2253 & 1455 \\
\hline $\begin{array}{l}\text { Кредиты, выданные по программам Фонда «Даму» в приори- } \\
\text { тетных секторах экономики, млрд тенге }\end{array}$ & 529 & 472 & 387 \\
\hline в том числе кредиты в обрабатывающей промышл енности & 315 & 198 & 203 \\
\hline $\begin{array}{l}\text { Доля кредитов, выданных по программам в приоритетных сек- } \\
\text { торах экономики, \% }\end{array}$ & 16,4 & 16,6 & 10,4 \\
\hline $\begin{array}{l}\text { Доля кредитов, выданных по программам Фонда «Даму» в об- } \\
\text { рабатывающей промышленности, \% }\end{array}$ & 21,1 & 17,2 & 14,0 \\
\hline
\end{tabular}

Примечание. Составлено авторами по: [Годовой отчет ... , 2018, с. 17]. 
тели $-26,5 \%$ и фермерские хозяйства $-14,4 \%$, для них местом закупок чаще выступает собственный регион.

Реализация товаров и услуг всеми субъектами частного предпринимательства чаще осуществляется на местных рынках. Пределы собственной области являются основным местом деятельности ИП $(91,4 \%)$ и меньше всех от местного рынка зависят предприятия среднего бизнеса $(54,6 \%)$, которые чаще, чем другие типы предприятий, работают в других областях Казахстана $(34,2 \%)$ и на экспорт $(11,2 \%)$. Надо обратить внимание на то, что доля предприятий, осуществляющих экспорт среди фермерских хозяйств, несколько больше, чем среди предприятий малого бизнеса и ИП (5,1\% против $4,4 \%$ и $1,7 \%$ ), что может служить косвенным признаком наличия экспортного потенциала у фермерских хозяйств.

Анализируя структуру экспорта и импорта субъектов МСП, можно выделить следующие группы товаров, которые указываются предпринимателями чаще всего (рис. 5).

Сравнивая результаты исследования с данными Комитета по статистике РК, можно отметить, что товары, экспортируемые МСП, согласно данным исследования входят в группы, составляющие минимальные доли в структуре экспорта РК. Это продукты животного и растительного происхождения, готовые продовольственные товары (3,5 \%), машины, оборудование, транспортные средства $(1,4 \%)$ и прочие товары (2,1\%), что указывает на весьма несущественный вклад предприятий МСП в экспортную деятельность. Импортируемые предприятиями МСП товары и услуги имеют более широкий спектр и выраженные доли, среди прочих товаров можно выделить 8 групп, доля импорта которых превышает внутренние покупки. Все это указывает на то, что деятельность субъектов МСП в РК отражает импорто-ориентированную экономику.

Если субъект хозяйствования относится к разряду МСП, является действующим или потенциальным экспортером несырьевой обработанной продукции, то он может стать участником программы «Экспорт 2020» и получить комплексную финансовую, сервисную и информационную поддержку, а также расширить объемы и географию своего экспорта.

В современных условиях стремление к эффективному использованию ресурсов ярко проявляется в объективном характере развития государственно-частного партнерства (далее - ГЧП). В Казахстане идет процесс внедрения ГЧП (принят закон «О Государственно-частном партнерстве» от 31 октября 2015 г., созданы специализированные организации по вопросам поддержки и развития ГЧП, начата реализация инвестиционных проектов). Текущая ситуация показала, что в РК осуществляется 102 проекта ГЧП, из них 8 республиканских (290 млрд тенге) и 94 местных проектов на сумму 873 млрд тенге.

Для осуществления деятельности в области ГЧП создано АО «Казахстанский центр государственно-частного партнерства» и ТОО «Центр сопровождения проектов государ-

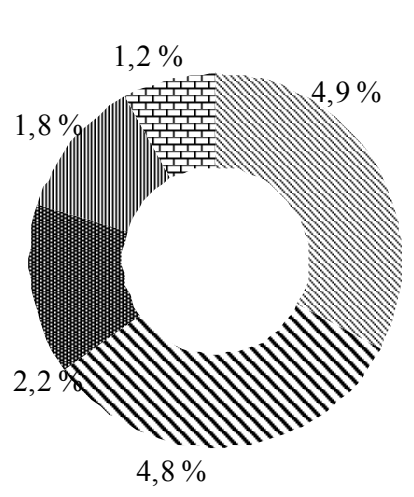

Экспорт

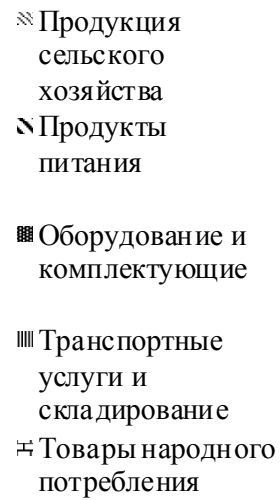
потребления

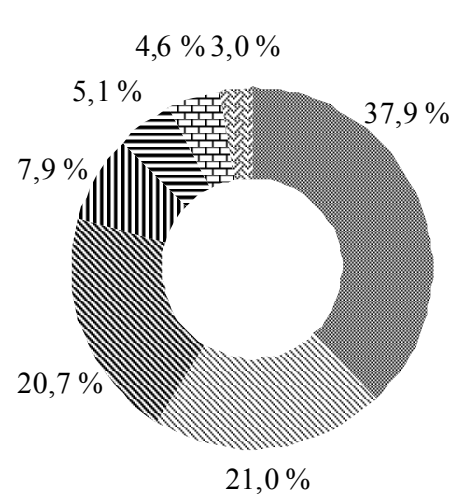

Товары народного
потребления
Стройм атериалы
жеборудование,
комплектующие
II Транспортные
услуги и склады
इ Услуги ИТ
Продукция
химпрома
Медикаменты

Импорт

Рис. 5. Состав и структура экспорта и импорта субъектов частного предпринимательства Примечание. Составлено авторами по: [Отчет ..., 2013]. 
ственно-частного партнерства». Основными целями и предметом деятельности Центра являются содействие инфраструктурному развитию путем оказания услуг по разработке документации и консультативному сопровождению инфраструктурных проектов [АО «Казахстанский ...].

В 2013 г. создана Национальная палата предпринимателей (далее - НПП) «Атамекен» [Национальная палата ...] для обеспечения благоприятных правовых, экономических и социальных условий ведения частного бизнеса, реализации предпринимательской инициативы и развития взаимовыгодного партнерства между бизнес-сообществом и органами государственной власти РК.

НПП «Атамекен» оказывает государственную нефинансовую помощь субъектам частного предпринимательства и населению с предпринимательской инициативой по следующим функциональным направлениям [Heфинансовая поддержка ...]: 1) информационно-аналитическое обеспечение предпринимательства; 2) развитие компетенций предпринимателей; 3 ) повышение производительности предпринимателей; 4) расширение деловых связей.

В рамках четвертого направления Единой Программы поддержки и развития бизнеса ДКБ-2020 - «Нефинансовые меры поддержки» - с 2015 г. НПП РК оказывает сервисную поддержку на местах через Центры обслуживания предпринимателей (далее- ЦОП) в областных центрах, городах республиканского значения и столице, а также через Центры поддержки предпринимателей (далее ЦПП) в районах. В 2018 г. обслужены 25,3 тыс. клиентов, им оказано более 34,6 тыс. консультаций в 18 ЦОП и 15 мобильных центрах поддержки предпринимательства.

В части реализации проектов ЦОП по итогам 2018 г. были сопровождены 6410 проектов по одобрению БВУ / ЛК / МФО заявок субъектов частного предпринимательства на получение финансовой поддержки по инструментам Фонда «Даму» [Годовой отчет ..., 2018, c. 16].

Сервисная поддержка включает в себя предоставление субъектам МСП специализированных услуг, которые направлены на совершенствование системы управления предпри- ятием в целях повышения его эффективности. В отраслевом разрезе субъекты МСП, получившие наибольшую долю сервисной поддержки в 2016-2018 гг., наблюдаются в оптовой и розничной торговле - 37,0 \%, предоставлении прочих видов услуг (сельское и лесное хозяйство, обрабатывающая промышленность, транспорт и складирование) - 23,9\%. Из всех предприятий, получивших сервисную поддержку, 99 \% относятся к малому бизнесу, а к среднему бизнесу - $1 \%$.

Общее количество мужчин-участников по итогам 2016-2018 гг. составило 55,6 \% и женщин-участниц $-44,4$ \%. Проявление подобного гендерного дисбаланса, в первую очередь связано со стереотипами: мужчины весьма болезненно реагируют на трансформацию социокультурных моделей поведения представителей обоих полов. Возрастной состав потребителей сервисных услуг представлен всеми возрастными категориями - от 17 и свыше 57 лет, основной категорией в 2016-2018 гг. являются участники от 30 до 49 лет - 48,7 \% от всего количества участников.

Согласно Единой программе поддержки и развития бизнеса ДКБ-2020 сервисная поддержка ведения действующей предпринимательской деятельности предоставляется по 8 видам услуг. Наибольшее количество консультаций было оказано по юридическим вопросам $(27,8 \%)$; по бухгалтерским и налоговым услугам (27,6 \%); по вопросам маркетинга $(23,5 \%)$. Наименьшее количество консультаций оказано по вопросам менеджмента $(2,4 \%)$ и полному сопровождению всего процесса по внедрению систем менеджмента $(2,7 \%)$.

Параллельно с программами финансовой поддержки Фондом «Даму» продолжается работа по реализации программ обучения и консультационной поддержки предпринимателей. В 2018 г. в рамках проекта «Дистанционная поддержка развития предпринимательства» на базе веб-платформы edu.damu.kz прошли обучение 7219 человек. Количество слушателей по компоненту «Обучение топменеджмента МСП», который реализуется в рамках ДКБ-2020, составило 2949 предпринимателей, в том числе в 2018 г. прошли обучение 424 человека [Годовой отчет ... , 2018, c. 17]. 
Позитивный тренд в ежегодном мировом рейтинге «Doing Business» наблюдается вследствие реализуемых комплексных мер поддержки и развития предпринимательства через государственную, рыночную и интегрированную подсистемы внешней среды косвенного воздействия.

\section{Заключение}

Анализ современного состояния предпринимательства и факторов его внешней среды в РК позволил сделать следующие выводы:

1) макросреда не способствует равномерному развитию сектора малого и среднего бизнеса по регионам страны, это связано с имеющимися диспропорциями в финансировании сектора МСП между регионами;

2) динамика изменения портфеля БВУ по кредитам малого и среднего бизнеса свидетельствует о том, что инструменты господдержки выполняют свои задачи, однако доля кредитов МСП в общем объеме кредитного портфеля страны остается крайне малой по сравнению с долей МСП в ВВП страны;

3) широкий доступ малого бизнеса к кредитам способствовал увеличению активности его инвестиционной деятельности, особенно в обрабатывающей промышленности, а темпы роста инвестиций в основной капитал МСП опережают темпы роста в целом рынка. Инвестиционная активность привела к росту количества субъектов МСП, появлению новых производственных предприятий, созданию новых рабочих мест - вклад малого и среднего бизнеса в занятость в обрабатывающей промышленности достиг $43,5 \%$, за счет инвестиций в основной капитал и наращивания производственных мощностей МСП увеличивает объемы выпуска продукции;

4) налоговые поступления в государственный бюджет от деятельности субъектов малого и среднего бизнеса ежегодно растут, однако налоговая политика государства по отношению к малому предпринимательству в большей степени носит фискальный, а не стимулирующий характер;

5) стратегические и координационные функции в экономических процессах развития предпринимательства реализуются государством через механизм Национальных институтов раз- вития, которые выступают в основном как специализированные финансовые учреждения. Основным государственным институтом развития предпринимательства выступает АО «Фонд развития предпринимательства “Даму”»;

6) товары, экспортируемые МСП, входят в группы, составляющие минимальные доли в структуре экспорта РК, что указывает на весьма несущественный вклад предприятий МСП в экспортную деятельность и отражает импортоориентированную экономику;

7) государственно-частное партнерство, ассоциации и союзы предпринимателей являются важными элементами интегрированной системы регулирования бизнеса в РК, они оказывают финансовые и нефинансовые меры (сервисные и консультационные услуги и обучение предпринимателей) поддержки субъектам частного предпринимательства.

Решение выявленных проблем во внешней среде предпринимательства РК позволит обеспечить повышение эффективности деятельности сектора МСП и создать условия для формирования конкурентоспособного государства.

\section{СПИСОК ЛИТЕРАТУРЫ}

Аганбегян, А. Формирование рыночного механизма экономического роста в России / А. Аганбегян // Проблемы теории и практики управления. -2005 . - № 2. - С. 34-38.

$\mathrm{AO}$ «Казахстанский центр государственно-частного партнерства». - Электрон. текстовые дан. Режим доступа: https://www.ppp-center.kz. Загл. с экрана.

Влияние программ Фонда «Даму» на развитие МСБ и диверсификацию экономики (макроэкономический эффект). - Астана : Байтерек, 2018. - 14 c.

Годовой отчет АО «Фонд развития предпринимательства “Даму”». - Астана : Байтерек, 2018. - $72 \mathrm{c}$.

Идрисов, М. М. Программа индустриально-инновационного развития Республики Казахстан на 2015-2019 гг. / М. М. Идрисов // Экономика, предпринимательство и право. - 2015. T. 5. - № 4. - C. 253-272. - DOI: https://doi.org/ 10.18334/Epp.5.4.2111.

Малое и среднее предпринимательство // Комитет по статистике МНЭ РК. - Электрон. текстовые дан. - Режим доступа: http://stat.gov.kz/ edition/publication. - Загл. с экрана. 
Национальный банк Казахстана // Официальный сайт. - Электрон. текстовые дан. - Режим доступа: https://www.nationalbank.kz. - Загл. с экрана.

Национальная палата предпринимателей РК «Атамекен». - Электрон. текстовые дан. - Режим доступа: http://palata.kz. - Загл. с экрана.

Нефинансовая поддержка МСБ в рамках Единой программы «ДКБ 2020». - Электрон. текстовые дан. - Режим доступа: https:// damu.kz/programmi/dorozhnaya-kartabiznesa-2020/nefinansovaya-podderzhkamsb-v-ramkakh-edinoy-programmy-dkb-2020.Загл. с экрана.

Отчет «Казахстан: Улучшение возможностей поддержки развития малого и среднего бизнеса». Астана : Центр исслед. «Сандж» для АБР, 2013. $148 \mathrm{c}$.

Отчет о состоянии и развитии малого и среднего предпринимательства в Казахстане и его регионах. - Астана : Байтерек, 2018. - 235 с.

Притворова, Т. П. Стратегический анализ бизнесмоделей социального предпринимательства в Казахстане / Т. П. Притворова, Е. С. Петренко, М. П. Аяганова // Экономика Центральной Азии. - 2017. - Т. 1, № 2. - С. 75-90. - DOI: https://doi.org/10.18334/.37975.

Райзберг, Б. А. Современный экономический словарь / Б. А. Райзберг, Л. Ш. Лозовский, Е. Б. Стародубцева. - М. : Инфра-М, 2011.-512 с.

Шишкин, Д. Г. Суть развития предпринимательских структур / Д. Г. Шишкин // Экономика предпринимательства. - 2013. - № 2 (224). C. 27-33.

Шувалов, В. А. Государственное регулирование инновационного развития регионов Казахстана / В. А. Шувалов // Российское предпринимательство. - 2015. - Т. 16, № 1. - С. 87-96. DOI: https://doi.org/10.18334/rp.16.1.47.

\section{REFERENCES}

Aganbegyan A. Formirovanie rynochnogo mekhanizma ekonomicheskogo rosta v Rossii [Formation of a Market Mechanism for Economic Growth in Russia]. Problemy teorii i praktiki upravleniya [Management Theory and Practice], 2005, no. 2, pp. 34-38.

AO «Kazakhstanskiy tsentr gosudarstvennochastnogo partnerstva» [ "Kazakhstan PublicPrivate Partnership Center” JSC]. URL: https:// www.ppp-center.kz.

Vliyanie programm Fonda «Damu» na razvitie MSB $i$ diversifikatsiyu ekonomiki (makroekonomicheskiy effekt) [Impact of
"Damu" Fund Programs on the Development of SMEs and the Diversification of the Economy (Macroeconomic Effect)]. Astana, Bayterek, 2018. 14 p.

Godovoy otchet $A O$ «Fond razvitiya predprinimatelstva «Damu» [Annual Report of "Damu" Entrepreneurship Development Fund" JSC]. Astana, Bayterek, 2018. 72 p.

Idrisov M.M. Programma industrialno-innovatsionnogo razvitiya Respubliki Kazakhstan na 2015-2019 gg. [The Program for Social-Innovation Development of the Republic of Kazakhstan in 2015-2019]. Ekonomika, predprinimatelstvo i pravo [Journal of Economics, Entrepreneurship and Law], 2015. vol. 5, no 4, pp 253-272. DOI: https://doi.org/ 10.18334/Epp.5.4.2111.

Maloe i srednee predprinimatelstvo[Small and Medium Enterprises]. Komitet po statistike MNE RK [Committee on Statistics of the Ministry of National Economy of the Republic of Kazakhstan]. URL: http://stat.gov.kz/edition/ publication/booklet.

Natsionalnyy bank Kazakhstana [National Bank of Kazakhstan]. Ofitsialnyy sayt [Official Website]. URL: https://www.nationalbank.kz.

Natsionalnaya palata predprinimateley $R K$ «Atameken» [“Atameken" National Chamber of Entrepreneurs of the Republic of Kazakhstan]. URL: http://palata.kz.

Nefinansovaya podderzhka MSB v ramkakh Edinoy programmy «DKB 2020»[Non-Financial Support for SMEs Within the Framework of the Unified Program “BRM 2020”]. URL: https:// damu.kz/programmi/dorozhnaya-karta-biznesa2020/nefinan sovaya-podderzhka-msb-vramkakh-edinoy-programmy-dkb-2020.

Otchet «Kazakhstan: Uluchshenie vozmozhnostey podderzhki razvitiya malogo i srednego biznesa» [Report "Kazakhstan: Improving Opportunities for Supporting the Development of Small and Medium Businesses"]. Astana, Tsentr issledovaniy «Sandzh» dlya ABR, 2013.148 p.

Otchet o sostoyanii $i$ razvitii malogo $i$ srednego predprinimatelstva $v$ Kazakhstane $i$ ego regionakh 2017 god [Report on the Status and Development of Small and Medium Enterprises in Kazakhstan and Its Regions, 2017]. Astana, Bayterek, 2018. 235 p.

Pritvorova T.P., Petrenko E.S., Ayaganova M.P. Strategicheskiy analiz biznes-modeley sotsialnogo predprinimatelstva v Kazakhstane [Strategic Analysis of Business Models of Social Entrepreneurship in Kazakhstan]. Ekonomika Tsentralnoy Azii [Journal of Central Asia Economy], 2017, vol. 1, no 2, pp. 75-90. DOI: https://doi.org/10.18334/.37975. 
Rayzberg B.A., Lozovskiy L.Sh., Starodubtseva E.B. Sovremennyy ekonomicheskiy slovar [Modern Economic Dictionary]. Moscow, Infra-M, 2011.512p. Shishkin D.G. Sut razvitiya predprinimatelskikh struktur [Essence of the Development of Business Structures]. Ekonomika predprinimatelstva, 2013, no. 2 (224), pp. 27-33.
Shuvalov V.A. Gosudarstvennoe regulirovanie innovatsionnogo razvitiya regionov Kazakhstana [State Regulation of Innovative Development of the Regions of Kazakhstan]. Rossiyskoe predprinimatelstvo [Russian Journal of Entrepreneurship], 2015, vol. 16, no. 1, pp. 87-96. DOI: https://doi.org/10.18334/rp.16.1.47.

\section{Information About the Authors}

Olga V. Mishulina, Doctor of Sciences (Economics), Professor, Department of Economics, Kostanay Branch of Chelyabinsk State University, Borodina St., 168A, 110006 Kostanay, Republic of Kazakhstan, olga_mishulina@mail.ru, https://orcid.org/0000-0002-1953-8842

Galina V. Panina, Candidate of Sciences (Economics), Associate Professor, Head of the Department of Economics, Kostanay Branch of Chelyabinsk State University, Borodina St., 168A, 110006 Kostanay, Republic of Kazakhstan, panina.galina@mail.ru, https://orcid.org/0000-0003-2768-5911

Natalya A. Baranova, Candidate of Sciences (Economics), Associate Professor, Department of Economics, Kostanay Branch of Chelyabinsk State University, Borodina St., 168A, 110006 Kostanay, Republic of Kazakhstan, natalivalentina@mail.ru, https://orcid.org/0000-0003-0610-7565

Natalya S. Gorelova, Candidate of Sciences (Economics), Associate Professor, Department of Economics, Kostanay Branch of Chelyabinsk State University, Borodina St., 168A, 110006 Kostanay, Republic of Kazakhstan, nata29091980@mail.ru, https://orcid.org/0000-0001-7179-3456

\section{Информация об авторах}

Ольга Владимировна Мишулина, доктор экономических наук, профессор кафедры экономики, Костанайский филиал Челябинского государственного университета, ул. Бородина, 168А, 110006 г. Костанай, Республика Казахстан, olga mishulina@mail.ru, https://orcid.org/0000-0002-1953-8842

Галина Викторовна Панина, кандидат экономических наук, доцент, заведующая кафедрой экономики, Костанайский филиал Челябинского государственного университета, ул. Бородина, 168А, 110006 г. Костанай, Республика Казахстан, panina.galina@mail.ru, https://orcid.org/0000-0003-2768-5911

Наталья Аркадьевна Баранова, кандидат экономических наук, доцент кафедры экономики, Костанайский филиал Челябинского государственного университета, ул. Бородина, 168A, 110006 г. Костанай, Республика Казахстан, natalivalentina@mail.ru, https://orcid.org/0000-0003-0610-7565

Наталья Сергеевна Горелова, кандидат экономических наук, доцент кафедры экономики, Костанайский филиал Челябинского государственного университета, ул. Бородина, 168A, 110006 г. Костанай, Республика Казахстан, nata29091980@mail.ru, https://orcid.org/0000-0001-7179-3456 